\title{
Electrochemical Sensor for Ultrasensitive Determination of Bisphenol A based on Gold Nanoparticles/ß-cyclodextrin Functionalized Reduced Graphene Oxide Nanocomposite
}

\author{
Yang Yun ${ }^{1,2, *}$ \\ ${ }^{1}$ Department of Application Chemistry, College of Science, Tianjin University of Commerce, \\ Tianjin, 300134, P. R. China \\ ${ }^{2}$ Tianjin Key Laboratory for Prevention and Control of Occupational and Environmental Hazards, \\ Logistics University of PAPF Tianjin,300162, P. R. China. \\ *E-mail: yyun@tjcu.edu.cn
}

doi: $10.20964 / 110402778$

Received: 7 January 2016 / Accepted: 29 January 2016 / Published: 1 March 2016

In this work, an electrochemical sensor based on a $\beta$-cyclodextrin functionalized reduced graphene oxide/gold nanoparticles ( $\beta-\mathrm{CD} / \mathrm{RGO} / \mathrm{Au})$ composite modified glassy carbon electrode (GCE) was proposed for the ultrasensitive detection of bisphenol A (BPA). The $\beta$-CD/RGO/Au nanocomposite was synthesized by a microwave heating method followed by an electrodeposition process. The prepared nanocomposite was carefully characterized by FTIR, Raman spectroscopy, UV-vis spectroscopy, SEM, EDX and XRD. The electrocatalytic oxidation of BPA on the modified GCE was investigated by cyclic voltammetry $(\mathrm{CV})$ and differential pulse voltammetry (DPV). The results showed that the $\beta-\mathrm{CD} / \mathrm{RGO} / \mathrm{Au}$ modified GCE could effectively enhance the electrochemical detection performance towards oxidation of BPA due to the synergetic effects of RGO and Au NPs with supramolecular recognition capability of $\beta$-CD. The proposed sensor exhibited excellent linear relationship between the detection current and BPA concentration in the range from 0.01 to $50 \mu \mathrm{M}$. The detection limit was estimated as $0.003 \mu \mathrm{M}(\mathrm{S} / \mathrm{N}=3)$. Moreover, the proposed BPA sensor has also been successfully used for determining BPA in various real samples.

Keywords: Graphene; Gold nanoparticle; Electrochemical; Electrodeposition; Bisphenol A

\section{$\underline{\text { FULL TEXT }}$}

(C) 2016 The Authors. Published by ESG (www.electrochemsci.org). This article is an open access article distributed under the terms and conditions of the Creative Commons Attribution license (http://creativecommons.org/licenses/by/4.0/). 